\title{
Use of immunoblot detection of serum antibodies in the diagnosis of chronic Pseudomonas aeruginosa lung infection in cystic fibrosis
}

\author{
G. H. SHAND, S. S. PEDERSEN, R. TILLING*, M. R. W. BROWN* and N. HøIBY
}

State Serum Institute, Department of Clinical Microbiology at Rigshospitalet, Juliane Maries Vej 28, 2 , Copenhagen, DK-2100, Denmark, and Microbiology Research Group, Department of PharmaceuticalSciences, University of Aston, Aston Triangle, Birmingham B4 7ET

\begin{abstract}
Summary. Antibodies to Pseudomonas aeruginosa were investigated in serum from cystic fibrosis (CF) patients by immunoblotting (Western blotting). The results were compared with determinations of precipitating antibodies in serum by crossed immune electrophoresis (CIE). The number of CIE precipitins is a sensitive and specific indication of infection and is used, with sputum bacteriology, to distinguish between colonisation and invasive lung infection. Immunoblotting was considerably more sensitive than CIE for detecting antibodies to $P$. aeruginosa. Paired serum samples from $64 \mathrm{CF}$ patients, taken before a diagnosis of $P$. aeruginosa lung infection and immediately afterwards, showed a marked increase in the number of serum antibodies with the onset of infection. The intensity of the reaction, as shown by the density of blotted bands, was also increased. Laser scanning densitometry of immunoblots, and of photographic negatives taken from them, was used to quantify the increases. Differences in the number and intensity of blotted bands were highly significant between the two groups. The reproducibility of the method was good. An immunoblot assay may be a sensitive and useful method for routine diagnosis of early $P$. aeruginosa lung infection in CF.
\end{abstract}

\section{Introduction}

Lung infection with Pseudomonas aeruginosa is the major cause of morbidity and mortality in patients with cystic fibrosis (CF) (Govan and Harris, 1986). Early in the disease, $P$. aeruginosa may be cultured sporadically from sputum samples while there is no outward sign of deteriotation in the patient's clinical condition. However, when $P$. aeruginosa is continually present in respiratory secretions, the patient's condition becomes worse with signs and symptoms of progressive respiratory disease (Wood et al., 1976). This decline is thought to represent the change from a relatively benign colonisation of the mucosa of the respiratory tract to an invasive and tissue-destroying infection (Høiby et al., 1987). The point at which colonisation becomes invasive infection is difficult to determine in practice.

Precipitating antibodies to $P$. aeruginosa in serum may be detected by crossed immune electrophoresis (CIE) (Høiby et al., 1977). Normal precipitin peak

Received 15 Dec. 1987; accepted 7 Mar. 1988. numbers in non-infected individuals are zero or one (Høiby, 1977a). In the Danish CF Centre at Rigshospitalet, colonisation with $P$. aeruginosa is distinguished from chronic broncho-pulmonary infection by the length of time during which sputum cultures have been positive and by an increase in precipitin peak numbers (Høiby et al., 1977). An infection diagnosed on these criteria has a poor prognosis and is an indication to begin regular intensive courses of antibiotic therapy to try to limit the damage to lung tissue from infection (Szaff $e t$ al., 1983; Pedersen et al., 1987a). Therefore, it is important to recognise the immunological responses to $P$. aeruginosa during the progress of disease to identify the early stages of chronic infection and determine the appropriate time to begin antibiotic therapy.

This study was undertaken to determine the sensitivity of immunoblotting (Western blotting) (Towbin et al., 1979) as a technique for detecting $P$. aeruginosa antibodies in serum and to compare it with CIE. Paired serum samples taken from patients before a diagnosis of $P$. aeruginosa lung infection and immediately afterwards were also 
investigated. A further aim of the study was to establish whether a diagnosis made on conventional principles correlated with alterations in serum antibodies detected by immunoblotting. The results of the immunoblotting study of paired serum samples were quantified by laser scanning densitometry.

\section{Materials and methods}

\section{Patients and bacteriology}

Diagnosis of CF was established on the basis of abnormal sweat electrolytes and exocrine pancreatic insufficiency (Wood et al., 1976). More than $80 \%$ of Danish CF patients are treated at the Danish CF Centre at Rigshospitalet. All the patients in the study attended the outpatient clinic at the Danish CF Centre at monthly intervals for physical evaluation and bacteriological investigations. $P$. aeruginosa was identified in sputum samples by the standard criteria (Cowan, 1974). Colonisation was defined as intermittent or continuous growth of $P$. aeruginosa from sputum, with $\leq 1$ precipitin peak detectable by CIE (Høiby et al., 1977). If $P$. aeruginosa had been cultured consistently from sputum for 6 months with the number of precipitin peaks always $\geq 2$ the condition was defined as chronic broncho-pulmonary infection.

\section{Serum}

Blood samples were obtained from patients at 3-4month intervals for determination of immune status. Blood was allowed to clot at room temperature and serum was separated by centrifugation at $2000 \mathrm{~g}$. Precipitating antibodies against $P$. aeruginosa, Staphylococcus aureus and Haemophilus influenzae were determined in each patient at least once a year by CIE. Serum samples not used immediately were stored at $-20^{\circ} \mathrm{C}$. Samples taken before the patients were infected with $P$. aeruginosa were available from 64 patients. Each of these samples was paired with the first sample taken from the same patient that had a precipitin number $\geq 2$. At the time of the second sample, the patients had given positive sputum cultures for an average of 6 months. The median time span between the two samples was 3.4 years (range $0 \cdot 1-$ 10.8 years). Control sera were obtained from 10 infant $\mathrm{CF}$ patients (six female, four male, median age 0.7 years) and 10 older $\mathrm{CF}$ patients (eight female, two male, median age 8.7 years) with no history of $P$. aeruginosa growth from sputum, and from 12 non-CF adult volunteers (six female, six male, median age $26 \cdot 6$ years) with no history of infection with P. aeruginosa.

\section{Preparation of $P$. aeruginosa standard antigen (StAg)}

Strains representing all 17 serotypes of $P$. aeruginosa were obtained from Dr O. S. Mikkelsen, State Serum
Institute, Copenhagen (Mikkelsen, 1970) and from the Cross Infection Laboratory, Public Health Laboratory Service, Colindale, London. Strains were grown on truche agar (peptone $5 \% \mathrm{w} / \mathrm{v}$, glucose $0.2 \% \mathrm{w} / \mathrm{v}, \mathrm{NaCl} 0.5 \%$ $\mathrm{w} / \mathrm{v}, \mathrm{pH} 7.5$ ) for $18 \mathrm{~h}$ at $35^{\circ} \mathrm{C}$. The cells were harvested with distilled water and centrifuged at $10000 \mathrm{~g}$ for 10 $\min$ at $4^{\circ} \mathrm{C}$. The bacterial pellet was resuspended in 5 volumes of distilled water and the cells were broken by sonication at $20 \mathrm{KHz}$ for $3 \times 45$-s bursts in an ice bath. The sonicate was centrifuged at $48000 \mathrm{~g}$ for $60 \mathrm{~min}$. The supernate $(\mathrm{StAg})$ containing soluble antigens was stored at $-20^{\circ} \mathrm{C}$ until use. The protein concentration of the antigen preparation was determined by refractometry with human IgG as a reference. A single batch of StAg with a protein concentration of $12.8 \mathrm{~g} / \mathrm{L}$ was used throughout the study.

\section{Sodium dodecyl sulphate-polyacrylamide gel electrophoresis (SDS-PAGE) and immunoblotting}

Antigen preparations were separated on $14 \%$ polyacrylamide gels with $5 \%$ stacking gels as described previously (Shand et al., 1985). Samples were denatured before loading on to the gel by heating at $100^{\circ} \mathrm{C}$ for $5 \mathrm{~min}$ with an equal quantity of a sample buffer containing SDS $2.5 \%$ $\mathrm{w} / \mathrm{v}$ and 2 -mercaptoethanol $2 \% \mathrm{v} / \mathrm{v}$.

Antigens were transferred to nitrocellulose (NC) paper (Schleicher \& Schuell, Dassell, W. Germany) by the method of Towbin et al. (1979). Blotting was performed at $30 \mathrm{~V}$ overnight in a Trans-blot apparatus (Bio-Rad, Richmond, CA, USA). To show complete qualitative transfer of proteins from the polyacrylamide gel, strips of NC paper were stained with amido black (Sigma) $1 \%$ $\mathrm{w} / \mathrm{v}$ immediately after transfer. After blotting, the polyacrylamide gel was also stained overnight with a solution of Coomassie brilliant blue (Sigma) $0.1 \% \mathrm{w} / \mathrm{v}$ in methanol $50 \% \mathrm{v} / \mathrm{v}$-acetic acid $10 \% \mathrm{v} / \mathrm{v}$, then destained in methanol $5 \% \mathrm{v} / \mathrm{v}$-acetic acid $10 \% \mathrm{v} / \mathrm{v}$, and compared with a similarly treated gel which had not been blotted.

After transfer, the NC paper was incubated with 10 mM Tris- $\mathrm{HCl}, \mathrm{NaCl} 0.85 \% \mathrm{w} / \mathrm{v}, \mathrm{pH} 7.4$ (TBS) containing Tween $200 \cdot 3 \% \mathrm{w} / \mathrm{v}$ for $1 \mathrm{~h}$ to saturate non-specific binding sites. The paper was then incubated with patient serum diluted 1 in 100 in TBS-Tween for $2 \mathrm{~h}$ at room temperature. The paper was washed for $3 \times 5 \mathrm{~min}$ with TBS-Tween then incubated for a further $2 \mathrm{~h}$ with horseradish peroxidase-conjugated rabbit anti-human IgG (Dakopatts, Glostrup, Denmark) diluted 1 in 500 in TBS-Tween. After incubation with the second antibody, NC paper was washed thoroughly with TBS and reactive sites visualised with 4-chloro-1-naphthol (Sigma) $25 \mu \mathrm{g} /$ $\mathrm{ml}$ in TBS containing $\mathrm{H}_{2} \mathrm{O}_{2} 0.01 \mathrm{v} / \mathrm{v}$.

In the study with paired serum samples, the denatured StAg was loaded directly on to the stacking gel with no comb. After transfer, the NC paper was cut into strips $0.5-\mathrm{cm}$ wide and the above reaction procedure was performed in perspex trays containing 12 separate wells.

Immunoblots were allowed to dry at room temperature and photographed immediately with copy film (Agfa Ortho Professional). 


\section{Crossed immune electrophoresis (CIE)}

Precipitating antibodies against $P$. aeruginosa were determined by CIE (Høiby, 1977a). StAg samples $(2 \mu \mathrm{l})$ were applied to wells punched in $1 \%$ agar gels (Indubiose A 37; L'Industrie Biologique Francaise S.A., France) on $5 \times 5 \mathrm{~cm}$ glass plates and separated in the first dimension at $10 \mathrm{~V} / \mathrm{cm}$ for $30 \mathrm{~min}$. Second dimension electrophoresis was at $1-2 \mathrm{~V} / \mathrm{cm}$ for $18 \mathrm{~h}$ into a $1 \%$ agarose gel containing patient's serum at a concentration of $15 \mu \mathrm{l} / \mathrm{cm}^{2}$. Immunoprecipitates were stained with Coomassie brilliant blue and the number of precipitin peaks counted.

\section{Statistical analysis}

Immunoblots and photographic negatives were scanned with an LK B 2202 Ultroscan Laser Densitometer run by an Apple II Europlus computer. The laser scan shows the antigen-antibody reactions as a number of peaks and the area under the curve as intensity. Paired $t^{-}$ tests and coefficients of variation on the number of peaks and intensities shown by laser scanning were calculated with a Statview $512+$ programme on an Apple Macintosh Plus computer. A p value $<0.05$ was considered to be significant.

The intra- and inter-tray and day-to-day variations in the number of peaks were determined after blotted strips were allowed to react with 10 serum samples of low $(n=3)$, medium $(n=3)$ and high $(n=4)$ antibody concentration as determined by CIE. Variations were calculated with the formula $\mathrm{SD}=\sqrt{ }\left(\sum \mathrm{d}^{2} / 2 \mathrm{n}\right)$ where $\mathrm{SD}$ is the standard deviation, $\sum \mathrm{d}^{2}$ is the sum of squared differences of double determinations of the same sample and $n$ is the number of samples.

\section{Evaluation of diagnostic significance}

The application of the assay of paired serum samples in the diagnosis of $P$. aeruginosa lung infection was determined by the method of Wulff (1981). The diagnostic sensitivity was the predictive value of a negative test $\left(\mathrm{PV}_{\text {neg }}\right)$. The diagnostic specificity was the predictive value of a positive test $\left(\mathrm{PV}_{\mathrm{pos}}\right)$. The nosographic sensitivity was the percentage of patients with the disease who had a positive test. The nosographic specificity was the percentage of patients without the disease who had a negative test.

\section{Results}

\section{Sensitivity of immunoblotting}

Serial doubling dilutions of StAg from an initial loading of $20 \mu \mathrm{g}$ were separated by SDS-PAGE, transferred to NC paper and allowed to react with patient's serum diluted 1 in 100 in TBS-Tween (fig. 1). The serum samples were taken from the same patient at different stages in the infection. Sample A was the first sample taken after a diagnosis of chronic broncho-pulmonary lung infection (fig. 1a); CIE at this time showed seven precipitin peaks. Sample B (fig. 1b) was taken 6 years later when there were 33 precipitin peaks. With both sera there were a number of antibody-antigen reactions seen in the immunoblot as dark horizontal bands. The number of bands was higher with the later sample, 37 bands in fig. $1 \mathrm{~b}$, lane 1 , compared with 28 bands in fig. 1, lane 1 . The bands in the later sample were also more intense. In both cases the number of bands diminished as the dilution increased. The highest dilution at which antigen was detected was 1 in 256 , equiavlent to $80 \mathrm{ng}$ protein (fig, la, lane 9). In tests with human serum albumin and Human Normal Immunoglobulin (State Serum Institute, Copenhagen) we found that the lower limit of detection of a single defined protein antigen in this system was $20 \mathrm{ng}$ (data not shown).

To determine the lower level of detection of serum antibodies, doubling dilutions of the serum samples A and B were allowed to react with $0.5-\mathrm{cm}$ strips of NC paper loaded with StAg equivalent to $10 \mu g$ of protein. At each dilution the number of bands decreased (figs. 2a and b) until at a dilution of 1 in 25600 none was visible. The greatest dilution at which a reaction could be seen was 1 in 12800 (figs. $2 \mathrm{a}$ and $\mathrm{b}$, lane 8). The sensitivity of this sytem can be expressed as the ratio of serum quantity to the area on which the serum reacts. With this measure, a figure for serum loading/unit area of $0.014 \mu \mathrm{l} / \mathrm{cm}^{2}$ was obtained for immunoblotting. By comparison, the highest dilution of the same serum that produced visible precipitin peaks in CIE was 1 in 8 for serum $A$, a loading of $1.9 \mu \mathrm{l} / \mathrm{cm}^{2}$, and 1 in 32 for serum $B$, a loading of $0.45 \mu \mathrm{l} / \mathrm{cm}^{2}$.

\section{Reaction of paired samples of patients' serum with St Ag}

P. aeruginosa StAg was separated by SDS-PAGE and the separated antigens transferred to $\mathrm{NC}$ paper. The StAg loading on the polyacrylamide gel was $340 \mu \mathrm{g}$ of protein $(10 \mu \mathrm{g} / 0.5 \mathrm{~cm})$. Amido black staining of NC paper and Coomassie blue staining of the gel after transfer showed that there was complete transfer of separated bands. After transfer, the NC paper was cut into strips $0.5 \mathrm{~cm}$ wide and each strip was incubated with a patient's serum in TBS-Tween; 128 paired samples from 64 patients were compared. Fig. 3 shows representative strips after reaction with serum from 12 patients. The 12 strips in fig. 3a were incubated with serum samples taken before $P$. aeruginosa infection was diagnosed and the strips in fig. $3 \mathrm{~b}$ with serum from the same 
a

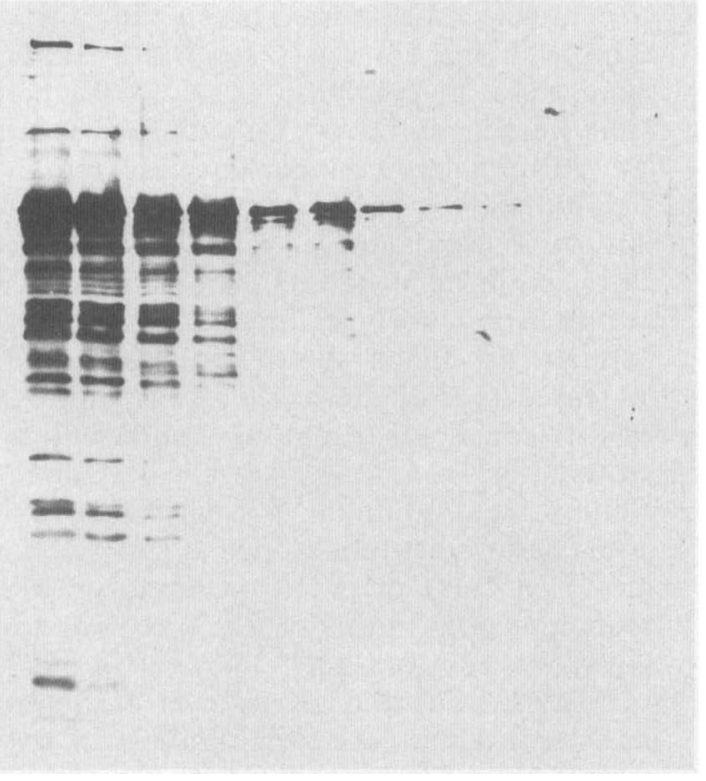

\section{9}

b

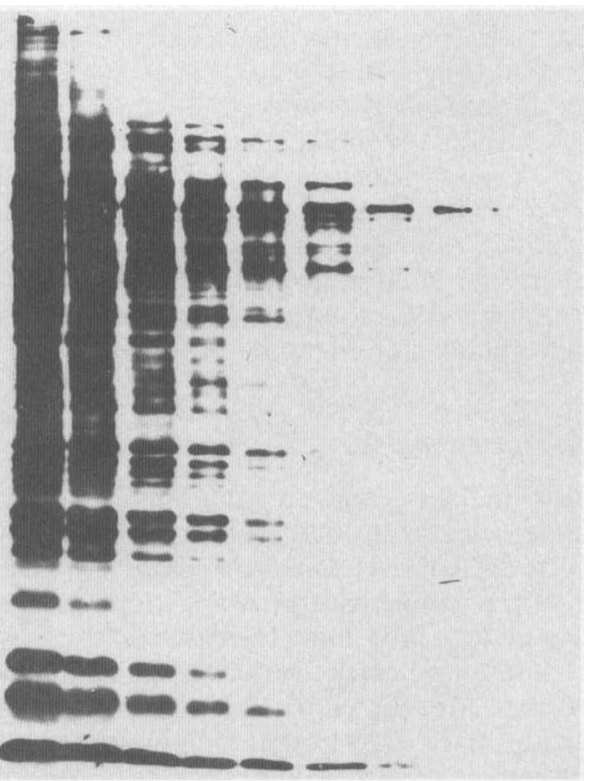

123456789

Fig. 1. Immunoblots of serial doubling dilutions of $P$. aeruginosa $\mathrm{StAg}$ treated with sera from a CF patient taken immediately after diagnosis of chronic $P$. aeruginosa lung infection (a) and 6 years later (b).

a

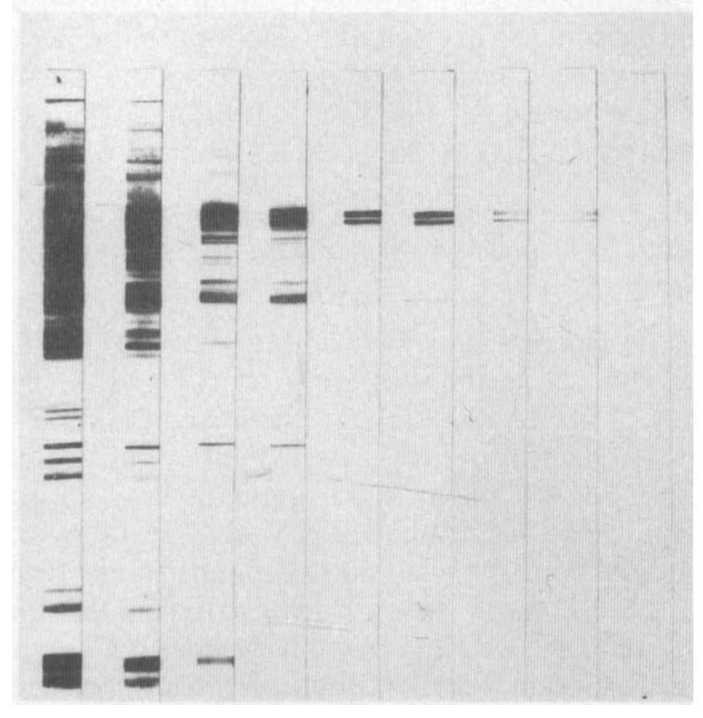

$\begin{array}{lllllllll}1 & 2 & 3 & 4 & 5 & 6 & 7 & 8 & 9\end{array}$ b

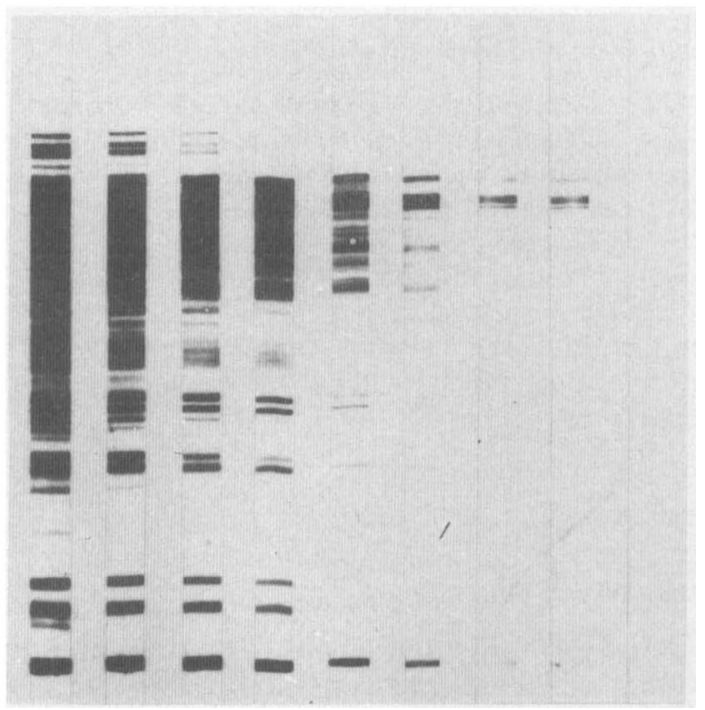

$\begin{array}{lllllllll}1 & 2 & 3 & 4 & 5 & 6 & 7 & 8 & 9\end{array}$

Fig. 2. Immunoblots of $P$. aeruginosa StAg treated with serial doubling dilutions of sera from a CF patient taken immediately after diagnosis of chronic $P$. aeruginosa lung infection (a) and 6 years later (b). 

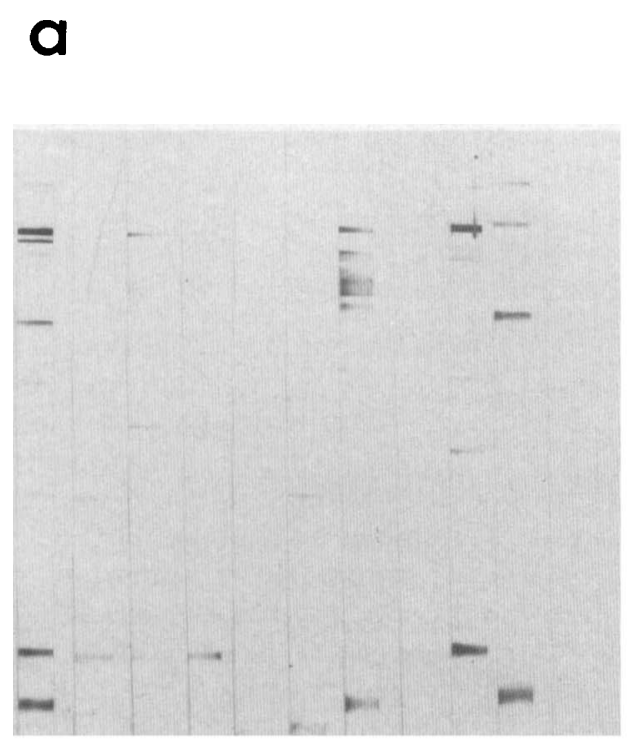

$\begin{array}{llllllllllll}1 & 2 & 3 & 4 & 5 & 6 & 7 & 8 & 9 & 1011 & 12\end{array}$ b

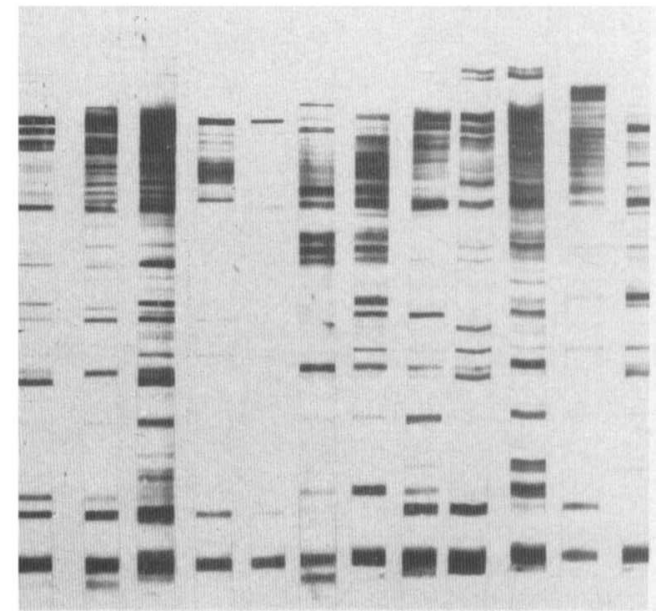

$\begin{array}{llllllllllll}1 & 2 & 3 & 4 & 5 & 6 & 7 & 8 & 9 & 1011 & 12\end{array}$

Fig. 3. Immunoblot analysis of 24 paired serum samples from $12 \mathrm{CF}$ patients allowed to react with $P$. aeruginosa StAg. Serum samples were taken before (a) and immediately after (b) diagnosis of $P$. aeruginosa lung infection.

patients immediately after diagnosis of chronic $P$. aeruginosa infection. there were more bands, and bands of greater intensity, in the strips treated with serum taken after infection. In some cases, e.g., fig. 3a strips 1 and 7, there are several bands indicating the presence of antibody in serum before a diagnosis of infection. Also some strips incubated with serum obtained after diagnosis of chronic infection, e.g., fig. 3 b strip 5 , show relatively few bands. However, when strips are placed side by side for comparison (as in fig. 4) there were always greater numbers of bands and more intense bands in the strips treated with serum taken after diagnosis of infection.

\section{Laser scanning densitometry}

The number of bands on each strip, and their relative intensity, were quantified by laser scanning densitometry of the strips and of photographic negatives taken immediately after blotting. The number of bands counted by laser scanning of blots and of the negatives taken from them were closely similar. The intensity measured from negatives was proportional to that measured directly from blots but was, on average, $23 \%$ lower. Fig. 4 shows typical scans from photographic negatives of blots of two paired serum samples. All the figures given below in the study of 64 paired samples refer to scanning of negatives. The average number of bands on the strips incubated with serum taken before a diagnosis of infection was 3.5 (range $0-13$ ) and with serum taken after diagnosis $15 \cdot 2$ (range 3-33). The number of bands on each strip in the before and after groups fell largely into two distributions (fig. 5a). Comparison of the number of bands in the two groups in a paired $t$-test (twotailed) gave a $t$ value of $12.91(\mathrm{p}<0.0001)$. Blots from 58 patients in the before-infection group showed seven or fewer bands while 56 of the afterinfection group showed eight or more. Taking seven bands as the dividing line between the two distributions gave a diagnostic sensitivity of $90.3 \%$ (95\% confidence limits (C.L.), 80.1-96.4\%) and a specificity of $87.9 \%(95 \%$ C.L., $77.5-94.6 \%)$ for the assay of paired samples. the nosographic sensitivity in the paired samples was $87.5 \%(95 \%$ C.L., $76.9-$ $94.5 \%)$ and the specificity $90.6 \%(95 \%$ C.L., $80 \cdot 7-$ $96.5 \%$ ).

Comparison of the intensity of bands in the two groups (the area under the scanning curve) gave a $t$ value of $6.7(\mathrm{p}<0.0001)$. Variations in intensity in each group (fig. 5b) were larger (coefficient of variation 108.5 ) than the variation in number of bands (coefficient of variation 49.1). The average intensity before infection was $140 \cdot 7$ (range 0-921) and after infection, $1258 \cdot 3$ (range 54-8676). CIE 


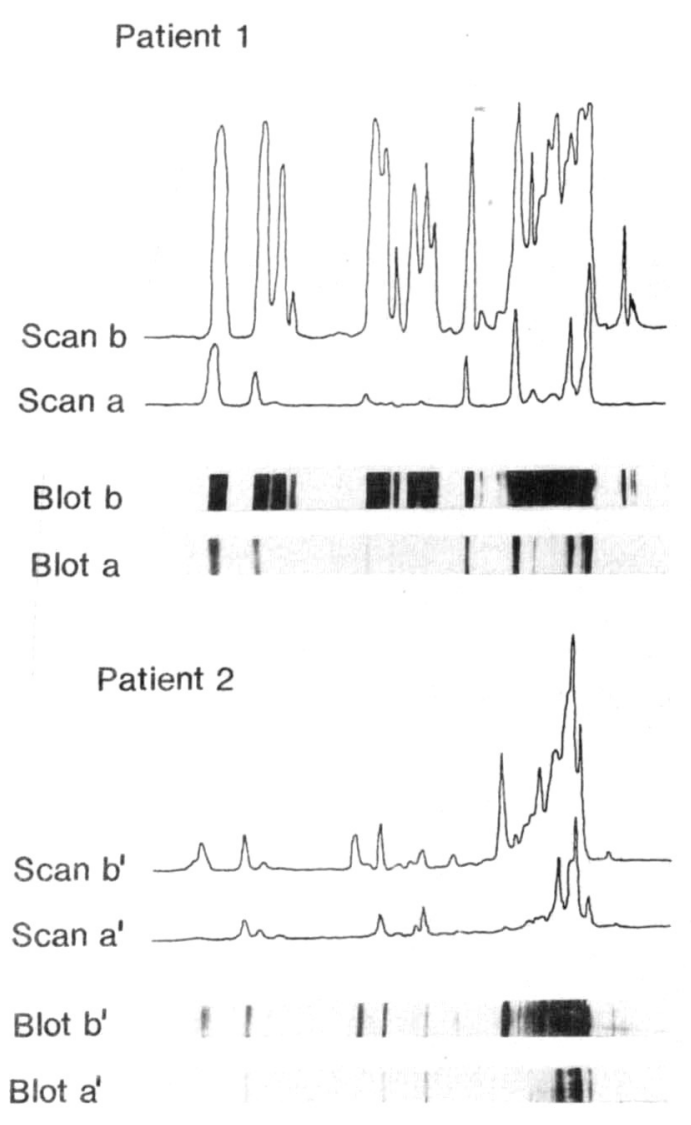

Fig. 4. Comparison of immunoblots of serum samples from two CF patients allowed to react with $P$. aeruginosa $\mathrm{StAg}$ and laser densitometer scans of their photographic negatives. Serum samples were taken before (blot a, $\mathbf{a}^{\prime} ;$ scan a, $\mathrm{a}^{\prime}$ ) and immediately after (blot b, $b^{\prime}$; scan b, $b^{\prime}$ ) diagnosis of chronic $P$. aeruginosalung infection.

precipitin peaks were in the range $2-8$ for the latter group (average 3.5$)$ and, by definition, either $0(60$ patients) or 1 ( 4 patients) in the before-infection group.

\section{Reaction of control sera with St Ag}

There was no reaction between StAg and serum samples from nine of the ten CF infant controls; the tenth gave one faint band. Of the older $\mathrm{CF}$ controls, six sera gave no reaction with $\mathrm{StAg}$, two showed one band, one had three bands and one had six bands. Six of the sera from non-CF adults did not react, three gave one band, two gave two and one gave four. All reactions of control sera with StAg were faint; the adult control with four bands had the highest intensity, 310 .

\section{Reproducibility}

The intra- and inter-tray and day-to-day variations between the number of bands on blotted strips with patients' sera were $1.7 \%, 5.7 \%$ and $3.8 \%$ respectively.

\section{Discussion}

An increase in the number of antibodies against $P$. aeruginosa in CF serum indicates invasive infection and correlates with a poor prognosis. The institution of regular intensive courses of antibiotic therapy as soon as chronic infection is diagnosed improves the prognosis significantly (Pedersen et al., 1987a). Therefore, it is important that a diagnosis of infection be made as early and as accurately as possible. Several immunological methods have been described for detection of antibodies in CF serum. CIE (Høiby, 1977 $a$ and $b$ ), enzyme-linked immunosorbent assay (ELISA) (Baltimore et al., 1986; Brett et al., 1986; Pedersen et al., 1987b) and radio-immune assay (RIA) (Moss et al., 1981; Dasgupta et al., 1987) with whole cells or whole-cell sonicates have all shown elevated antibody titres in CF serum. This study shows that immunoblotting is also a valuable indicator of antibodies to $P$. aeruginosa in serum from $\mathrm{CF}$ patients. These methods provide complementary information; used together they could give a comprehensive picture of antibody development in infection.

When compared with CIE on the basis of the minimum loading of serum/unit area to show a response, immunoblotting was more sensitive by a factor of 32. This sensitivity means that the immunoblotting method is more economical of patient's serum than CIE. Typically in this system we use only $5-10 \mu \mathrm{l}$ of serum.

Immunoblotting also detects very low levels of antigen and shows more antibody-antigen reactions than CIE at equivalent concentrations. For example, fig. 1 shows 28 bands with a serum sample that gave seven precipitin peaks in CIE and 37 bands with a serum sample that gave 33 precipitin peaks. This may reflect the greater sensitivity of the blotting method, or some of the reactions detected by blotting may not be due to precipitating antibodies and, thus would not form peaks in CIE. Also, the method of preparation of StAg may involve the physical breakdown of cell components which are then separated according to molecular weight in SDS-PAGE and appear to be different antigens. There is a general correlation between CIE and immunoblotting; sera that contained 

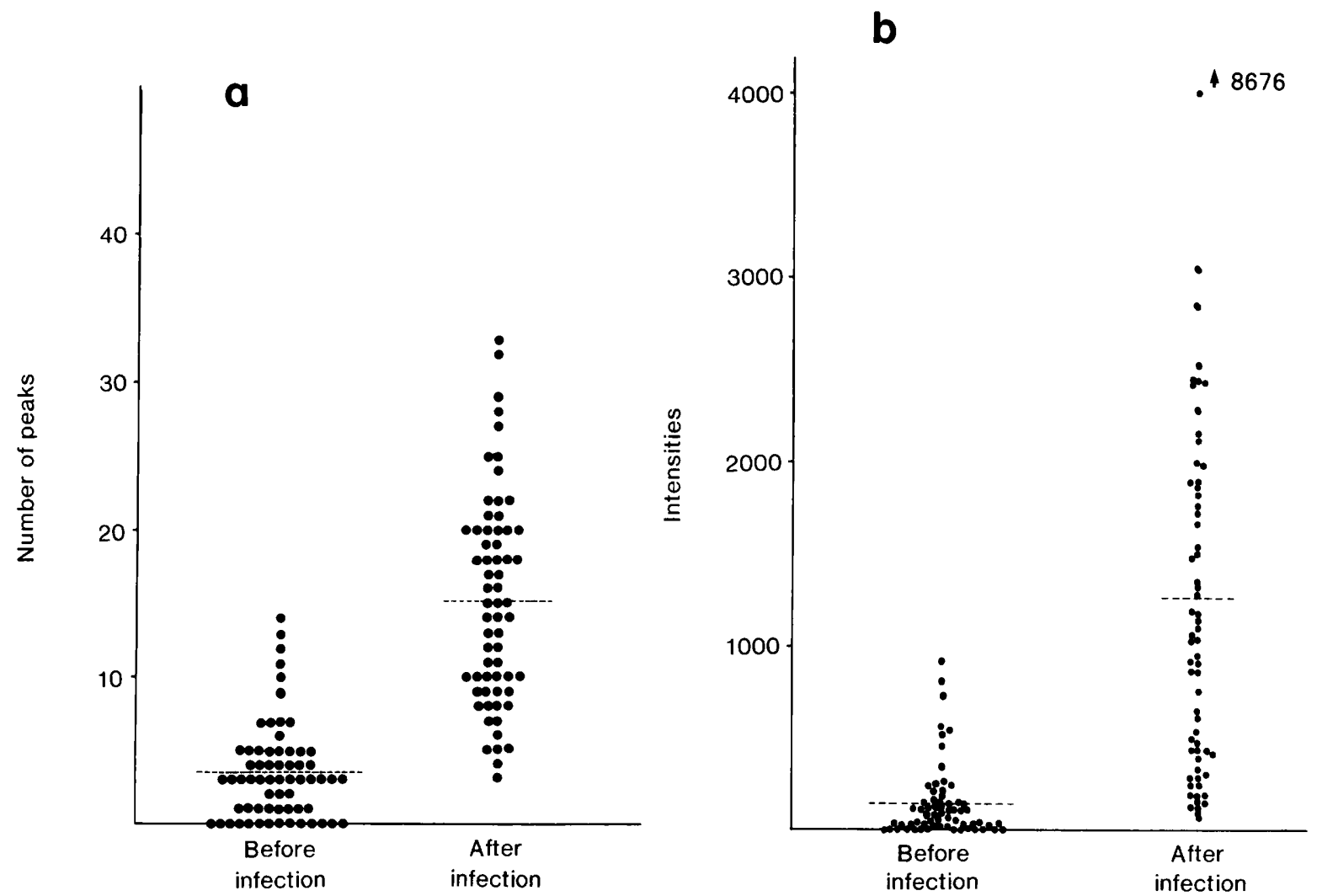

Fig. 5. Distribution of peaks (a) and intensities (b) detected by laser scanning densitometry of immunoblots from serum samples taken before and immediately after a diagnosis of chronic $P$. aeruginosa lung infection. One intensity value (8676) fell outside the scale of the figure. The dotted line indicates median values.

greater numbers of precipitins also showed greater numbers of bands by immunoblotting.

The study of paired serum samples taken from patients before and after diagnosis of $P$. aeruginosa infection demonstrated an increase in the number of antigen-antibody reactions in every patient studied. The difference in the number of bands identified by immunoblotting in the two groups was statistically highly significant as was the difference in intensities. The significance of the increase in intensity of individual peaks has not been studied but it seems likely to be related to antibody concentration (Towbin and Gordon, 1984). We are currently working with immunoblotting and ELISA techniques (Fomsgaard and Dinesen, 1987) to evaluate antibody concentration and affinity in CF serum. The diagnostic sensitivity and specificity of immunoblotting are high and an assay based on increased numbers of antibodies detected by this method may be a useful tool in the diagnosis of infection. Reproducibility is good and the method lends itself well to routine use. After electrophoretic transfer to $\mathrm{NC}$ the $\mathrm{StAg}$ remains antigenically active for at least 9 months if stored at $-20^{\circ} \mathrm{C}$ (data not shown). A batch of strips may be prepared and stored at $-20^{\circ} \mathrm{C}$ and used individually when required. The assay of individual strips can be performed easily in a small test tube or home-made plastic tray with readily available laboratory chemicals. Laser scanning of strips is not necessary for routine diagnosis because the difference between blots can be seen easily with the naked eye (see figs. 3 and 4). Counting of bands with the naked eye agreed closely with counting by laser scanner up to about 25 . Above this number, laser scanning of the blots, or photographic negatives taken from them, resolved bands which the unaided eye could not (see fig. 4 blot b, scan b). Laser scanning also gave an objective quantification of bands and intensity and had the further benefit of a permanent record stored on computer disk. The use of photographic negatives also allows a permanent record to be kept and overcomes one disadvantage of immunoblots whose colour tends to fade with time. 
There is some overlap in the number of bands detected by immunoblotting in the before- and after-infection groups. This implies the presence of antibodies against $P$. aeruginosa in some of the serum samples taken before diagnosis of infection. CIE showed zero or one precipitin peak in these samples. This may reflect the greater sensitivity of immunoblotting and indicate an early antibody response to colonising bacteria. An overlap in antibody titres between colonised and chronicallyinfected patients has also been noted in an ELISA study with whole cells (Brett et al., 1986). These overlaps may be due to cross-reactive antibodies generated by infection with organisms other than $P$. aeruginosa. Such infections are common in the CF lung (Pedersen et al., 1986). Cross reactions can be demonstrated between $P$. aeruginosa StAg and hyperimmune serum raised in rabbits to cell sonicates of several gram-negative bacteria, especially $H$. influenzae (unpublished observations). Antibody titres against $P$. aeruginosa increase with age (Granstrøm et al., 1984; Pedersen et al., 1987b), possibly as a result of increases in cross-reacting antibodies (Høiby, 1975). The number of observations we have made of antibody responses in 'normal' serum is too small to draw any firm conclusions. The low frequency of reactions between StAg and control serum from CF infants and

\section{REFERENCES}

Anwar H, Brown M R W, Day A, Weller P H 1984 Outer membrane antigens of mucoid Pseudomonas aeruginosa isolated directly from the sputum of a cystic fibrosis patient. FEMS Microbiology Letters 24 : 235-239.

Baltimore R S, Fick R B, Fino L 1986 Antibody to multiple mucoid strains of Pseudomonas aeruginosa in patients with cystic fibrosis, measured by an enzynme-linked immunosorbent assay. Pediatric Research 20: 1085-1090.

Brett M M, Ghoneim A T M, Littlewood J M 1986 Serum antibodies to Pseudomonas aeruginosa in cystic fibrosis. Archives of Disease in Childhood 61 : 1114-1120.

Cowan S T 1974 Cowan and Steel's Manual for the identification of medical bacteria, 2nd edn. Cambridge University Press, Cambridge.

Cryz S R 1984 Pseudomonas aeruginosa infections. In : Germanier R (ed) Bacterial vaccines. Academic Press, London, p 317.

Dasgupta M K et al. 1987 Combined evaluation of circulating immune complexes and antibodies to Pseudomonas aeruginosa as an immunologic profile in relation to pulmonary function in cystic fibrosis. Journal of Clinical Immunology 7 : 51-58.

Fernandes P B, Kim C, Cundy K R, Huang N N 1981 Antibodies to cell envelope proteins of Pseudomonas aeruginosa in cystic fibrosis patients. Infection and Immunity 33: 527-532.

Fomsgaard A, Dinesen B 1987 ELISA for human IgG and IgM anti-lipopolysaccharide antibodies with indirect standardization. Journal of Immunoassay 8: 333-350.

Govan J R W, Harris G S 1986 Pseudomonas aeruginosa and older children indicates that the reactions observed in the 64 patients before and after infection were specific to antibodies against $P$. aeruginosa.

Several cell components of $P$. aeruginosa stimulate an antibody response (Cryz, 1984). The presence of antibodies specific to outer-membrane proteins (Fernandes et al., 1981; Hancock et al., 1984) and to iron-regulated membrane proteins and flagella (Anwar et al., 1984) has been demonstrated in CF serum. However, it is not known how the chronological appearance of antibodies to these components correlates with the clinical condition of the patient. Perhaps significantly, antibodies specific to $P$. aeruginosa mucoid exopolysaccharide have been reported to confer resistance to colonisation in CF patients (Pier et al., 1987). We are currently working to identify and separate the individual components of the StAg preparation. It may then be possible to correlate the appearance of antibodies to specific antigens with colonisation or the onset of invasive infection. The high sensitivity of immunoblotting may enable us to arrive at an earlier and more precise diagnosis of the stages of infection than is possible at present.

GHS was supported by a grant from the Leo Research Foundation. We are grateful for the technical assistance of Ellen Jørgensen.

cystic fibrosis: unusual bacterial adaptation and pathogenesis. Microbiological Sciences 3: 302-308.

Granstrøm et al. 1984 Relation between antibody response to Pseudomonas aeruginosa exoproteins and colonization/ infection in patients with cystic fibrosis. Acta Paediatrica Scandinavica 73: 772-777.

Hancock R E W, Mouat E C A, Speert D P 1984 Quantitation and identification of antibodies to outer-membrane proteins of Pseudomonas aeruginosa in sera of patients with cystic fibrosis. Journal of Infectious Diseases 149: 220-226.

Høiby N 1975 Cross-reactions between Pseudomonas aeruginosa and thirty-six other bacterial species. Scandinavian Journal of Immunology 4 Suppl 2: 187-196.

Høiby N 1977 a Antibodies against Pseudomonas aeruginosa in sera from normal persons and from patients colonized with mucoid or non-mucoid Pseudomonas aeruginosa. Results obtained by means of crossed immunoelectrophoresis. Acta Pathologica et Microbiologica Scandinavica Section C. 85: 142-148.

Høiby N $1977 b$ Pseudomonas aeruginosa infection in cystic fibrosis. Diagnostic and prognostic significance of Pseudomonas aeruginosa precipitins determined by crossed immunoelectrophoresis. A survey. Acta Pathologica et Microbiologica Scandinavica Section C Suppl. 262: 3-96.

Høiby N, Flensborg E W, Beck B, Friis B, Jacobsen S V, Jacobsen L 1977 Pseudomonas aeruginosa infection in cystic fibrosis. Diagnostic and prognostic significance of Pseudomonas aeruginosa precipitins determined by means of crossed immunoelectrophoresis. Scandinavian Journal of Respiratory Diseases 58: 65-79. 
Høiby N, Döring G, Schiøtz P O 1987 Pathogenic mechanism of chronic Pseudomonas aeruginosa infections in cystic fibrosis patients. Antibiotics and Chemotherapy $39: 60-76$.

Mikkelsen O S 1970 Serotyping of Pseudomonas aeruginosa 2. Results of an O group classification. Acta Pathologica et Microbiologica Scandinavica Section B 78: 163-175.

Moss R B, Hsu Y P, Lewiston N J $1981{ }^{125} \mathrm{I}$-Clq-binding and specific antibodies as indicators of pulmonary disease activity in cystic fibrosis. Journal of Pediatrics 99: 215-222.

Pedersen S S, Jensen T, Pressler T, Høiby N, Rosendal K 1986 Does centralized treatment of cystic fibrosis increase the rick of Pseudomonas aeruginosa infection? Acta Paediatrica Scandinavica 75 : 840-845.

Pedersen S S, Jensen T, Høiby N, Koch C, Flensborg E W 1987 a Management of Pseudomonas aeruginosa lung infection in Danish cystic fibrosis patients. Acta Paediatrica Scandinvica 76: 955-961.

Pedersen S S, Espersen F, Høiby N $1987 b$ Diagnosis of chronic Pseudomonas aeruginosa infection in cystic fibrosis by enzyme-linked immunosorbent assay. Journal of Clinical Microbiology 25: 1830-1836.

Pier G B et al. 1987 Opsonophagocytic killing antibody to Pseudomonas aeruginosa mucoid exopolysaccharide in older noncolonized patients with cystic fibrosis. New England Journal of Medicine 317: 793-798.

Shand G H, Anwar H, Kadurugamuwa J, Brown M R W, Silverman S H, Melling J 1985 In vivo evidence that bacteria in urinary tract infection grow under iron-restricted conditions. Infection and Immunity 48: 35-39.

Szaff M, Høiby N, Flensborg E W 1983 Frequent antibiotic therapy improves survival of cystic fibrosis patients with chronic Pseudomonas aeruginosa infection. Acta Paediatrica Scandinavica 72: 651-657.

Towbin H, Staehelin T, Gordon J 1979 Electrophoretic transfer proteins from polyacrylamide gels to nitrocellulose sheets: Procedure and some applications. Proceedings of the National Academy of Sciences of the USA 76: 4350-4354.

Towbin H, Gordon J 1984 Immunoblotting and dot immunoblotting-current status and outlook. Journal of Immunological Methods 72: 313-340.

Wood R E, Boat T F, Doershuk 1976 Cystic Fibrosis. American Review of Respiratory Diseases 113 : 833-878.

Wulff H R 1981 Rational diagnosis and treatment : an introduction to clinical decision-making. Blackwell Scientific Publications, Oxford. 